\title{
Type X collagen levels are elevated in serum from human osteoarthritis patients and associated with biomarkers of cartilage degradation and inflammation
}

Yi He${ }^{1}$, Anne Sofie Siebuhrr, Niels Ulrik Brandt-Hansen ${ }^{1}$, Jianxia Wang ${ }^{2}$, Di Su², Qinlong Zheng ${ }^{2}$, Ole Simonsen ${ }^{3}$, Kristian Kjær Petersen ${ }^{3,4}$, Lars Arendt-Nielsen ${ }^{4}$, Thomas Eskehave ${ }^{5}$, Hans Christian Hoeck ${ }^{5}$, Morten Asser Karsdal ${ }^{1}$ and Anne C Bay-Jensen ${ }^{1 *}$

\begin{abstract}
Background: Osteoarthritis $(\mathrm{OA})$ is the most common degenerative joint disease, of which the pathogenesis is inadequately understood. Hypertrophy-like changes have been observed as part of the progression of OA. The aim of the study was to develop and characterize a novel biomarker of chondrocytes hypertrophy and investigate how this marker was associated with cartilage degradation and inflammation in patients with various degrees of OA.

Methods: A competitive ELISA, C-Col10, applying a well-characterized monoclonal antibody was developed as a biomarker of chondrocyte hypertrophy through measurement of type X collagen (ColX). The levels of C-Col10, C2M (matrix metalloproteinase-derived fragments of type II collagen) and hsCRP (high sensitive C-reactive protein) were quantified by ELISAs in serum of $271 \mathrm{OA}$ patients stratified by Kellgren-Lawrence (KL) score $0-4$. Associations between serum levels of the three biomarkers (log transformed) were analyzed by Pearson's correlation and differences in C-Col10 levels between patients with high and low levels of inflammation measured by hsCRP were analyzed by ANOVA.

Results: We developed a C-Col10 assay measuring the C-terminus of ColX. We found significantly higher levels of ColX in patients with $\mathrm{KL}$ score 2 compared to patients with no radiographic evidence of OA (KLO) $(p=0.04)$. Levels of ColX were significantly elevated in OA patients with above normal hsCRP levels $(p<0.0001)$, as well as significantly correlated with levels of C2M ( $r=0.55, p<0.0001)$, which suggested that chondrocyte hypertrophy was associated with inflammation and cartilage degradation. There was no correlation between C2M and hsCRP. Age and BMl adjustment didn't change the results. Immuno-staining revealed that CoIX was predominately located around the hypertrophic chondrocytes and the clustered chondrocytes indicating that C-Col10 measures may be linked to cartilage hypertrophic changes.

Conclusions: We developed a novel assay, C-Col10, for measurement of chondrocyte hypertrophy and found its levels significantly elevated in OA patients with $\mathrm{KL}$ score of 2, and also in OA patients with above normal hsCRP levels. Concentration of C-Col10 strongly correlated with levels of C2M, a marker of cartilage destruction. The data suggest that chondrocyte hypertrophy and subsequent collagen $X$ fragmentation seem to be increased in a subset of patients with inflammatory OA.
\end{abstract}

Keywords: Hypertrophic chondrocytes, Osteoarthritis, Type X collagen, Cartilage degradation, Biomarkers, Type II collagen, Inflammation

\footnotetext{
* Correspondence: acbj@nordicbioscience.com

${ }^{1}$ Nordic Bioscience, Herlev Hovedgade 207, DK-2730 Herlev, Denmark

Full list of author information is available at the end of the article
} 


\section{Background}

Osteoarthritis (OA) is the most common joint disease, which is characterized by cartilage damage and loss of joint function. The high prevalence, with the accompanying disabilities of OA results in a huge economic burden on society [1]. However, the molecular mechanism of OA disease remains partly understood and is more complicated than expected. Not only the changes in extracellular matrix (ECM) composition, but also changes in the metabolism of chondrocytes contribute to the progression of OA [2]. The events of chondrocytes hypertrophy differentiation including matrix degradation, neo-vessels invasion from subchondral bone and matrix calcification have been observed in the progression of OA, which mimic the processes during skeletal development by endochondral ossification [3-6]. Runt-related transcription factor 2 (RUNX2), a transcription regulator of type X collagen, has been reported to be involved in the development of OA disease [7]. The critical role of hypertrophy chondrocytes have been summarized in several good reviews [8-10].

Type X collagen (ColX) is a well-established marker for hypertrophic chondrocytes differentiation, which is a nonfibrillar collagen consisting of three identical alpha 1 chains. Each chain has three domains: a short triple helix domain flanked by a bigger globular domain ( $\mathrm{NC1}$ domain) at the carboxyl end and a short non-collagenous domain (NC2 domain) at the amino end [11]. The molecular weight of each alpha 1 chain is $64 \mathrm{kDa}$ of human ColX, of which triple helix domain is $42 \mathrm{kDa}$ [12]. ColX is susceptible to interstitial collagenase and gelatinase cleavage at two distinct sites within triple helix domain generating fragments [13]. ColX is considered to be synthesized specifically by hypertrophic chondrocytes of growth plate during the development of long bone [14]. Immunoelectron microscopy shows that individual ColX molecules can rapidly assemble into a hexagonal lattice via carboxy-terminal globular domains, which play the important role in modifying the cartilage matrix for the subsequent bone formation during endochondral ossification [15]. Besides the maintenance of tissue stiffness, several other roles have been suggested, including regulating chondrocytes metabolism and interacting with hypertrophic chondrocytes through cell adhesion molecules such as integrins [16]. There is increasing evidence that the expression of ColX is elevated in human OA cartilage as a result of chondrocytes hypertrophy and cartilage calcification [17-19]. The upregulation of ColX has been reported in experimental animal OA models as well [20-23].

$\mathrm{OA}$ is thought to be a "non-inflammatory" joint disease due to low level of inflammation in contrast to other joint disease such as rheumatoid arthritis (RA). Despite that, inflammation has indeed been considered to contribute to the symptoms and progression of OA $[24,25]$. Circulating markers of inflammation - such as C-reactive protein (CRP), a common diagnostic marker for chronic inflammatory disease such as RA - has been shown to be elevated in subsets of OA patients as compared to a sample population without disease [26]. Elevated serum CRP may reflect inflammation in affected joints, like synovitis, which is associated with clinical symptoms such as pain [27]. It was reported by Cecil et al. that inflammation-induced chondrocytes hypertrophy is contributed significantly to the progression of OA [28]. Thus, it is interesting to investigate the relationship between hypertrophy and inflammation in OA.

The aim of this study was to develop an immunoassay (C-Col10) to determine the levels of ColX in blood and to investigate the relationships between chondrocyte hypertrophy, cartilage degradation and systemic inflammation by measuring three biomarkers in serum from $271 \mathrm{OA}$ patients: C-Col10, C2M and high sensitive (hs) CRP. Serum $\mathrm{C} 2 \mathrm{M}$ measures circulating fragments of type II collagen, a surrogate marker of cartilage degradation. C2M was found to be significantly higher in patients with moderate/severe OA compared to patients with mild OA or healthy agematched controls [29], as well as in patients with ankylosing spondylitis (AS) compared to controls [30].

\section{Methods}

\section{Materials}

Materials and chemicals were purchased from SigmaAldrich (Broendby, Denmark) or VWR (Roedovre, Denmark) if not stated otherwise.

\section{Serum samples from $O A$ patients}

Serum samples were retrieved from C4Pain study ( $\mathrm{n}=$ 271 with Kellgren-Lawrence score ranging from 0-4). In this study, the OA population was recruited based on intensity of knee joint pain, ranging from 0 to 100 on a Western Ontario and McMaster Universities Osteoarthritis Index (WOMAC) pain scale. Two plain X-ray examinations in standing position were performed. Serum was collected upon overnight fasting prior to surgery or during consultation. The study was approved by The Ethical Committee of Northern Jutland (VEK no.: N-20100094). It was conducted according to the Principal of Good Clinical Practice and according to the Declaration of Helsinki. All patients provided written informed consent.

\section{Development and characterization of anti-ColX monoclonal antibody}

A specific peptide, SFSGFLVAPM obtained from Cterminus of $\mathrm{NC} 1$ domain of ColX was synthesized and conjugated to maleimide-activated keyhole-limpet hemocyanin (KLH, Pierce, Beijing, China) as immunogen. The immunogens were used to immunize female, seven-week-old Balb/C mice by repeating injections. The monoclonal antibody was produced by standard 
method. The monoclonal antibody was screened and characterized by competitive ELISA by using the specific peptide (SFSGFLVAPM), the truncated peptide (SFSGFLVA) without last 2 amino acids and the nonsense peptide (DMDYLPRVPNQ).

\section{Western Blotting of U2-OS cell lysates}

Further characterization of ColX monoclonal antibody, NB509-11G8, was conducted by western blotting with cell lysates of human osteosarcoma cell line, U2-OS expressing type $\mathrm{X}$ collagen. The cell lysates were prepared using fresh RIPA buffer ( $25 \mathrm{mM}$ Tris- $\mathrm{HCl}$ pH7.6, $150 \mathrm{mM}$ $\mathrm{NaCl}, 1$ Sodium deoxycholate acid and fresh EDTA-free protease inhibitor cocktail tablet (Roche, USA)). U2-OS lysates were separated in 4-12 Bis-Tris gradient gel and electrically transferred to polyvinylidene fluoride (PVDF) membrane. After blocking, the membrane was incubated with $1 \mu \mathrm{g} / \mathrm{ml}$ NB509-11G8 antibody or X53 (positive control for intact ColX) at $4^{\circ} \mathrm{C}$ overnight. To confirm the specificity of bands, the peptide inhibition western blotting was performed in parallel with adding $3 \mu \mathrm{g} / \mathrm{ml}$ selection peptide or truncated peptide into NB509-11G8 antibody solution, then immediately incubated with the membrane. After incubation with goat anti-mouse secondary antibody (1:5000) at RT (room temperature) for $2 \mathrm{hr}$, the membrane was washed and detected using enhanced chemiluminescence (ECL) western blotting substrate (GE healthcare, Denmark). The bands were visualized through exposure to X-ray film.

To investigate the possibility of NB509-11G8 detecting type $\mathrm{X}$ collagen fragments, the in vitro digestion of U2-OS lysates was carried out by degradation of collagenase (C6885, Sigma) with two concentrations, $50 \mu \mathrm{g} / \mathrm{ml}$ and $5 \mu \mathrm{g} / \mathrm{ml}$. The cleavage reactions were carried out for $1 \mathrm{hr}$, $2 \mathrm{hr}, 4 \mathrm{hr}$ or overnight $(20 \pm 1 \mathrm{hr})$ at $37^{\circ} \mathrm{C}$. These mixtures were submitted to western blotting and detected by NB509-11G8 antibody and X53.

\section{Western blotting of human $O A$ cartilage extracts}

Cartilage biopsies were obtained from 3 OA patients who underwent total knee arthroplasty. Proteins were extracted with $1 \mathrm{ml} 4 \mathrm{M}$ guanidinium chloride $(\mathrm{GuHCl})$ containing $50 \mathrm{mM}$ Sodium Acetate, $10 \mathrm{mM}$ EDTA, $0.1 \mathrm{M}$ Hexanoic Acid, pH5.8 at $4{ }^{\circ} \mathrm{C}$ for $48 \mathrm{hr}$. The extract was separated from cartilage residue by centrifugation $(800 \mathrm{~g})$ at $4{ }^{\circ} \mathrm{C}$ for $10 \mathrm{~min}$ and stored at $-70^{\circ} \mathrm{C}$ prior to use. Inhibition western blotting as mentioned above was applied to detect type $\mathrm{X}$ collagen in three human $\mathrm{OA}$ cartilage extracts (human skeletal muscle extract used as negative control from Biochain, USA).

\section{Development and characterization of the C-Col10 ELISA}

The competitive C-Col10 ELISA was developed with optimal mix of buffer, incubation time, temperature and
Table 1 Sequence alignment of the last 10 aa of NC-1 domain of ColX a1 chain in different species

\begin{tabular}{lcc}
\hline Species & Sequence & Database \\
\hline Homo sapiens $^{1}$ & SFSGFLVAPM & GenBank:CAA46236.1 \\
Mus musculus $^{2}$ & SFSGFLVAPM & GenBank:CAA46237.1 \\
Bos taurus $^{3}$ & SFSGFLVAPM & NCBI: NP_777059.1 \\
Rattus norvegicus $^{4}$ & SFSGFLVAP! & GenBank: CAA10518.1 \\
Canis lupus familiaris $^{5}$ & SFSGFLVAPM & NCBI: XP_003639449.1 \\
Equus caballus $^{6}$ & SFSGFLVAPM & NCBI: XP_001504151.1
\end{tabular}

${ }^{1}$ Human; ${ }^{2}$ Mouse; ${ }^{3}$ Cattle; ${ }^{4}$ Rat; ${ }^{5}$ Dog; ${ }^{6}$ Horse.

concentrations of reagents. The final protocol was as follows: $100 \mu \mathrm{l}$ biotinylated peptide was added to a streptavidin pre-coated plate and incubated at $20^{\circ} \mathrm{C}$ for $30 \mathrm{~min}$. Next, the plate was washed 5 times with standard wash buffer. $20 \mu \mathrm{l}$ standards or samples together with $100 \mu \mathrm{l}$ peroxidase labeled antibody were added to the plate and incubated at $4^{\circ} \mathrm{C}$ overnight with shaking. After that, the wells were washed 5 times and $100 \mu \mathrm{l} /$ well 3,3',5,5'tetramethylbenzidine (TMB) was added and incubated in the dark at $20^{\circ} \mathrm{C}$ for $15 \mathrm{~min}$. Lastly, $100 \mu \mathrm{l} /$ well stopping solution $\left(0.1 \mathrm{H}_{2} \mathrm{SO}_{4}\right)$ was added and the colorimetric reaction was measured at $450 \mathrm{~nm}$ with reference at $650 \mathrm{~nm}$. Technical assay validation was done according to the international guide.

\section{Biochemical markers}

ColX, cartilage degradation and systemic inflammation were quantified in serum of $271 \mathrm{OA}$ patients by 3 assays: C-Col10, C2M and hsCRP (Siemens 74701). C-Col10 assay was followed the protocol above mentioned, while hsCRP assay was strictly followed the protocol recommended in the kit manual. C2M ELISA assay was followed

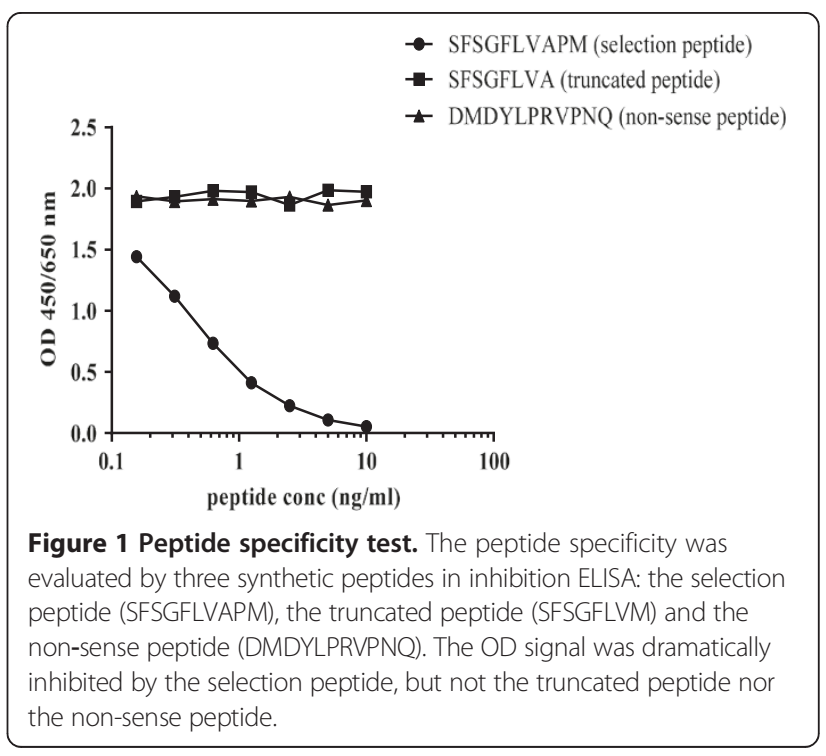



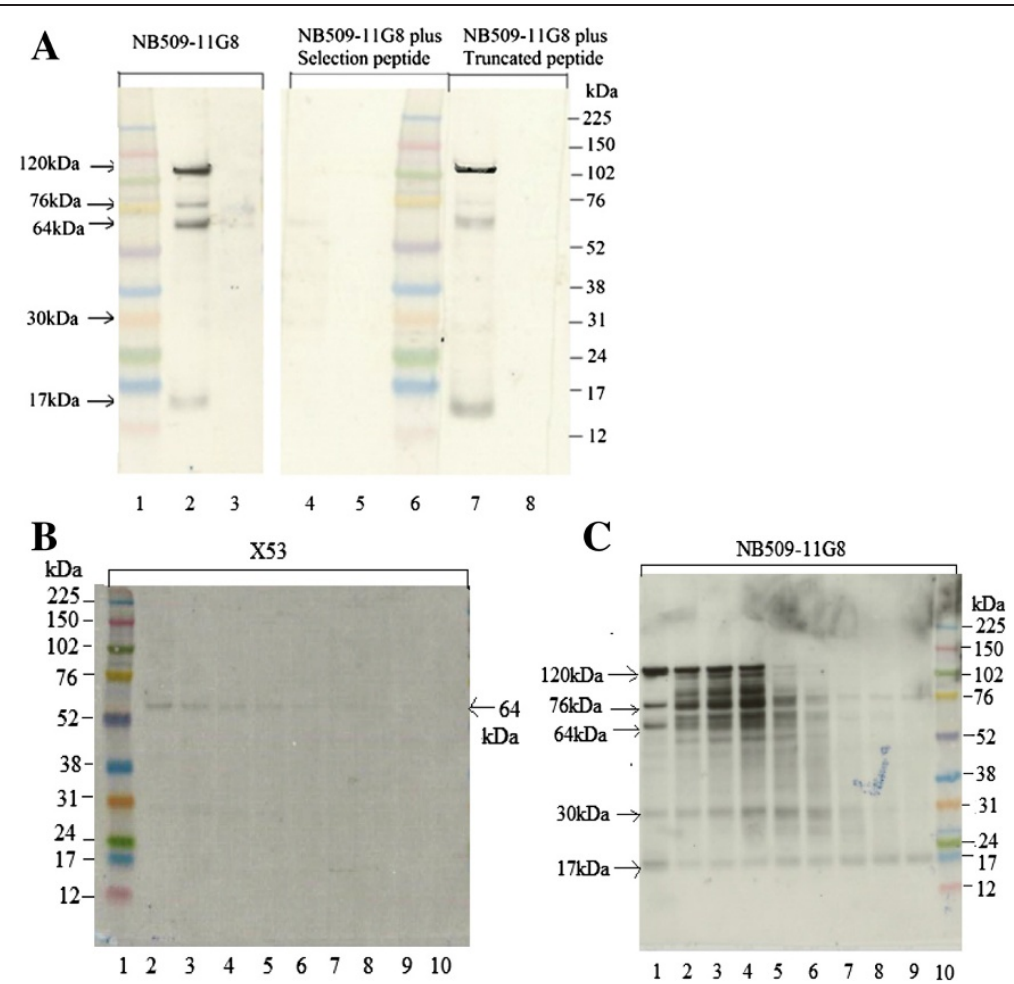

Figure 2 Western blotting on U2-OS cell lysates. A. Lane 1 and 6: marker. Lane 2, 4 and 7: U2-OS cell lysates; Lane 3, 5 and 8: RIPA buffer. 5 bands have been identified in U2-OS cell lysates by NB509-11G8. Moreover, these bands can be completely blocked by the selection peptide, but not the truncated peptide. B. U2-OS cell lysates in vitro digestion products detected by X53 on western blotting. Lane1: marker. Lane 2: U2-OS cell lysates; Lane 3-6: U2-OS cell lysates incubated with $5 \mathrm{ug} / \mathrm{ml}$ collagenase for $1 \mathrm{hr}, 2 \mathrm{hr}, 4 \mathrm{hr}$ or overnight. Lane7-10: U2-OS cell lysates incubated with $50 \mathrm{ug} / \mathrm{ml}$ collagenase for $1 \mathrm{hr}, 2 \mathrm{hr}, 4 \mathrm{hr}$ or overnight. X53 only detected $64 \mathrm{kDa}$ a 1 chain. The intensity of this chain decreased with the incubation time and the amount of collagenase. C. U2-OS cell lysates in vitro digestion products detected by NB509-11G8 on western blotting. Lane 1: U2-OS cell lysates; Lane 2-5: U2-OS cell lysates incubated with $5 \mathrm{ug} / \mathrm{ml}$ collagenase for 1 hr, 2 hr, 4 hr and overnight. Lane6-9: U2-OS cell lysates incubated with $50 \mathrm{ug} / \mathrm{ml}$ collagenase for $1 \mathrm{hr}, 2 \mathrm{hr}, 4 \mathrm{hr}$ or overnight. Lane10: marker. The degradation of ColX by collagenase exhibited a time- and dosedependent pattern.

the protocol described previously, which has been used in several studies $[30,31]$.

\section{In situ detection of ColX in human OA cartilage}

Cartilage biopsies from 3 OA patients were taken from OA patients undergoing total knee replacement surgery at the Department of Orthopedics at Sygehus Vendsyssel, Frederikshavn, Denmark. The retrieval of specimens complied with international ethical guidelines for handling human samples and patient information. All participants signed an informed consent form and the study was approved by Danish National Ethical Committees under the Act on Research Ethics Review of Health Research Projects (journal no. N-20110031).

The cartilage biopsies were fixed in formaldehyde, decalcified with EDTA, and embedded in paraffin. Sections were cut into $5 \mu \mathrm{m}$ adjacent sections and melted at $60^{\circ} \mathrm{C}$, deparaffinized and hydrated. Endogenous Peroxidase activity was blocked with $\mathrm{H}_{2} \mathrm{O}_{2}$ in 99 ethanol by incubation at RT for $20 \mathrm{~min}$. For C-Col10, antigen retrieval was done by Pronase E (Roche) at $37^{\circ} \mathrm{C}$ for $15 \mathrm{~min}$. For
$\mathrm{C} 2 \mathrm{M}$, citrate buffer pH6.0 at $60^{\circ} \mathrm{C}$ overnight was used to unmask antigen. Unspecific protein binding was blocked with 0.5 casein in TBS buffer at RT for $30 \mathrm{~min}$. Afterward, NB509- 11 G8 antibody, the C2M antibody or normal mouse IgG (negative control) were incubated with sections at $4^{\circ} \mathrm{C}$ overnight. Immunoactivity was detected by using peroxidase labeled secondary antibody and diminobenzidine (DAB, Dako, Denmark) as chromogen. Sections were counter stained with Mayer's acidic hematoxylin for $12 \mathrm{sec}$. Pictures were taken with a digital camera (Olympus C5050) on a microscope (Olympus BX60).

\section{Statistics}

Statistic analysis of correlation was performed using GraphPad Prism ${ }^{@}$ version 5. Levels of the 3 biomarkers in serum samples were shown as mean [95-CI]. Oneway ANOVA was applied when compare biomarker levels. Correlations between levels of biomarkers were done by Pearson's test on log transformed data. 


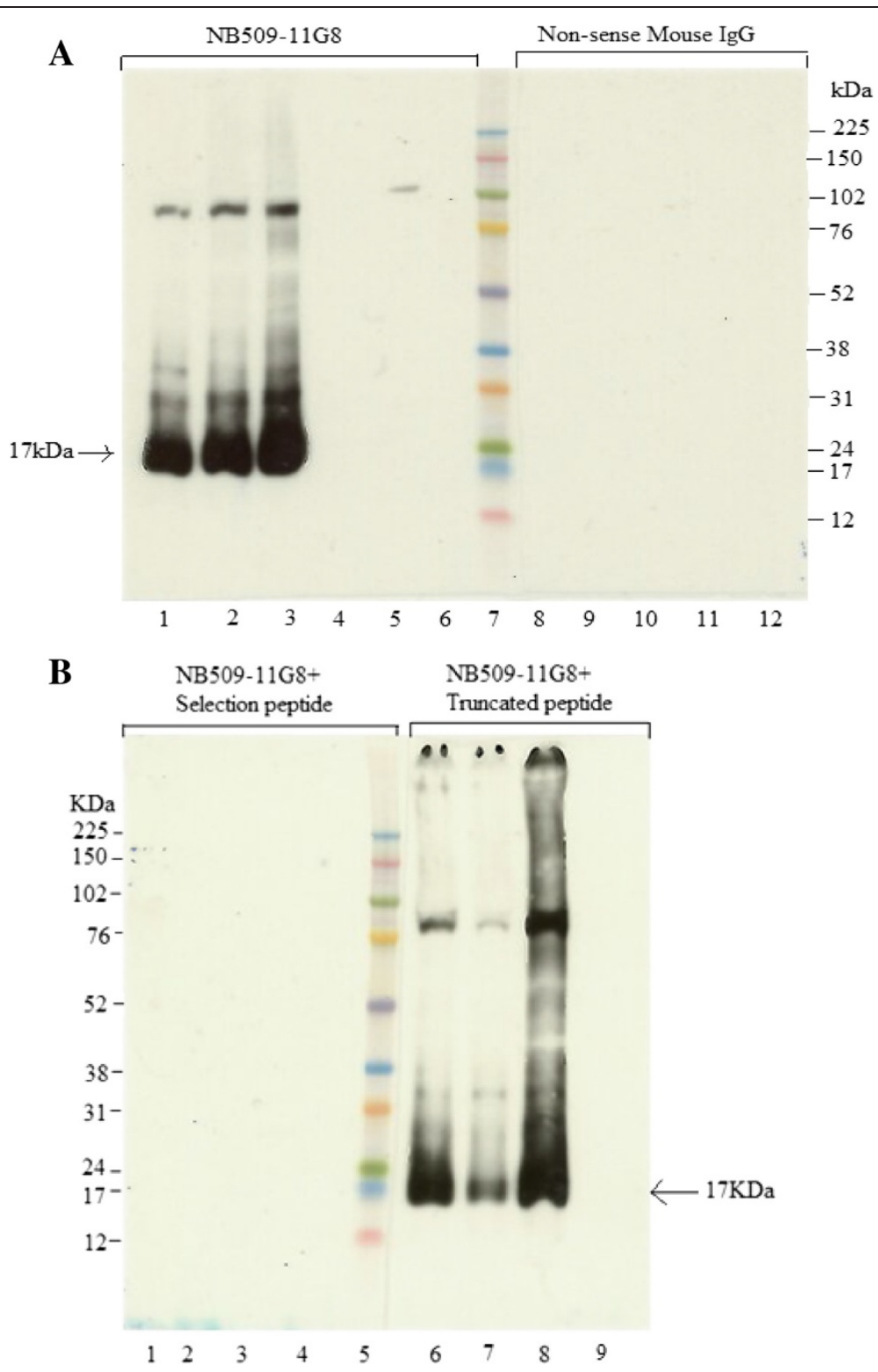

Figure 3 Western blotting on human OA cartilage extract. A. Lane1 and 8: human OA cartilage extract1; Lane 2 and 9: human OA cartilage extract 2; Lane 3 and 10: human OA cartilage extract3; Lane 4 and 11: GuHCl extraction buffer. Lane 5 and 12: human skeletal muscle extract; Lane 6: muscle extraction buffer. Lane 7: marker. Lane 1-7 was incubated with NB509-11G8, while Lane 8-12 was incubated with non-sense mouse lgG. The same size of $17 \mathrm{kDa}$ band was visualized in three cartilage extract, but not in the muscle extract. No any band was detected in neither cartilage extract nor muscle extract by non-sense mouse $\mathrm{lgG}$. B. Peptide inhibition western blotting on human OA cartilage extracts. Lane 5: marker; Lane 1and 6: human OA cartilage extract1; Lane 2 and 7: human OA cartilage extract2; Lane 3 and 8: human OA cartilage extract3. Lane 4 and 9: GuHCl extraction buffer. The $17 \mathrm{kDa}$ bands in 3 human OA extracts were blocked by selected peptide, but not truncated peptide.

\section{Results}

The specificity of the monoclonal antibody NB509-11G8

The sequence alignment of species is shown in Table 1.

The signal of NB509-11G8 (IgG1, k) was displaced by increasing concentration of selection peptide (SFSGFL VAPM), but neither by the truncated peptide (SFSGFL VA) nor by the non-sense peptide (DMDYLPRVPNQ) (Figure 1), indicating that NB509-11G8 specifically recognized the unique $\mathrm{C}$-terminus of $\mathrm{NC} 1$ domain.
Detection of ColX by the monoclonal antibody NB509-11G8 in U2-OS cell lysates and human cartilage extracts

U2-OS is a widely used human osteo/chondroblast-like cell line derived from malignant bone tumors with the capacity to express ColX [32]. Commercial X53 antibody recognized only intact $\alpha 1$ chain (Figure $2 \mathrm{~B}$, lane 2), whereas NB509-11G8 detected five bands (Figure 2A): i) a $17 \mathrm{kDa}$ band, corresponding to a previously reported band generated by intestinal collagenase (MMP-1) [13]; 
Table 2 Summary of technical performance for 3 biomarkers assays

\begin{tabular}{lccc}
\hline & C-Col10 $(\mathbf{p g} / \mathbf{m l})$ & hsCRP $(\mu \mathbf{g} / \mathbf{m l})$ & C2M (pg/ml) \\
\hline Assay specifications & & & \\
Slope of standard curve & 1.23 & n. a. & 0.96 \\
IC50, pg/ml & 363 & n. a. & 440 \\
Intra-assay CV\% & 4.19 & n. a. & 3.95 \\
Inter-assay CV\% & 13.18 & $<5$ & 9.88 \\
Lower limit of detection & 24 & n. a. & n. a. \\
Quantifiable range & $40-7300$ & $0.2-10$ & $30-1700$ \\
\hline
\end{tabular}

C-Col10: C-terminus of ColX assay; C2M: MMP-derived collagen type II fragment assay; hsCRP: high sensitive CRP assay. n.a.: not available.

ii) a $30 \mathrm{kDa}$ band with a unknown cleavage site in triple helix domain; iii) a $64 \mathrm{kDa}$ band representing the intact $\alpha 1$ strand; iv) an unknown $76 \mathrm{kDa}$ band, and v) an unknown $120 \mathrm{kDa}$ band. The difference in bands detected by X53 and NB509-11G8 might be explained by the fact that they target against different sequences. The epitope of X53 has been suggested to recognize a pepsin-resistant epitope overlapping collagenous domain and portion of NC-1 domain. All bands were absent, when the selection peptide was added into NB509-11G8 solution, indicating that all bands carry the C-terminus of NC-1 domain.

The degradation of ColX by collagenase showed a timeand dose- dependent pattern, which was demonstrated using both X53 and NB509-11G8 (Figure 2B and 2C). The $\alpha 1$ chain following digestion exhibited greatly reduced intensity when stained by X53 (Figure 2B). Digestion with $5 \mu \mathrm{g} / \mathrm{ml}$ collagenase released more fragments detected by NB509-11G8(Figure 2C, lane 2-4) than before treatment (lane 1). The $120 \mathrm{kDa}$ band became weaker over incubation time and completely disappeared after overnight incubation, whereas a $32 \mathrm{kDa}$ band was more clearly visible. Meanwhile, $50 \mu \mathrm{g} / \mathrm{ml}$ collagenase aggressively degraded ColX (lane 6-9). The $17 \mathrm{kDa}$ band were unaffected by the collagenase treatment.

A major $17 \mathrm{kDa}$-fragment was identified in three different human OA cartilage extracts (Figure 3A), but not in human skeletal muscle extract. No any band was detected by the non-sense mouse IgG (negative control). Moreover, the bands were completely blocked by the selection peptide instead of the truncated peptide, demonstrating the $17 \mathrm{kDa}$ fragment contains the $\mathrm{C}$-terminus of ColX (Figure 3B).

\section{The technical performance of the C-Col10 ELISA}

A competitive ELISA was developed by applying the NB509-11G8 monoclonal antibody. The technical performance of this ELISA is summarized in Table 2. The LLOD was $24 \mathrm{pg} / \mathrm{ml}$. The intra-assay $\mathrm{CV}$ was 4.19 and the inter-assay $\mathrm{CV}$ was 13.2. The measurement range was $40-7300 \mathrm{pg} / \mathrm{ml}$ and the IC50 was $363 \mathrm{pg} / \mathrm{ml}$. The dilution recovery and peptide spiking recovery test in human serum were $100 \pm 20$ within the measurement rang of the assay.

\section{Biomarker levels in the C4Pain cohort}

271 subjects were divided into 5 groups based on their KL scores (Table 3). There was significant difference in the CCol10 levels between KL0 and KL2 $(p=0.04)$. The mean value of C-Col10 in KL3 and KL 4 groups were 1.5 and 1.7 times higher but not statistically significant compared to KL0 group respectively, which could be high variation of individual C-Col10 levels in KL3 and KL4 groups. There was a trend towards elevated $\mathrm{C} 2 \mathrm{M}$ level with increased KL score, but there was no significant difference existing between any two groups. The hsCRP levels did not show any correlation with the degree of KL score. There was a significant correlation between C-Col10 and

Table 3 Serum levels of 3 biomarkers in 271 samples divided by KL score

\begin{tabular}{|c|c|c|c|c|c|c|c|}
\hline \multirow{2}{*}{$\begin{array}{c}\mathrm{KL} \\
\text { scroe }\end{array}$} & \multirow{2}{*}{$\begin{array}{c}\text { Number } \\
\text { of } \\
\text { Female/ } \\
\text { male }\end{array}$} & \multirow[t]{2}{*}{ Age } & \multirow[t]{2}{*}{ BMI } & \multicolumn{2}{|c|}{ C-Col10 } & \multirow[t]{2}{*}{$\mathrm{hsCRP} \mu \mathrm{g} / \mathrm{ml}$} & \multirow[t]{2}{*}{$\mathrm{C} 2 \mathrm{M} \mathrm{pg} / \mathrm{ml}$} \\
\hline & & & & $\mathrm{pg} / \mathrm{ml}$ & $P$ value & & \\
\hline 0 & $4 / 6$ & $62.5(57.3-67.7)$ & $25.4(23.7-27.0)$ & $52(24-80)$ & n. a. & $2.94(-0.75-6.64)$ & $287(245-325)$ \\
\hline 1 & $31 / 28$ & $63.7(61.6-65.8)$ & $27.0(26.0-28.1)$ & 65 (54-76) & 0.11 & $2.12(1.44-2.80)$ & $299(270-327)$ \\
\hline 2 & $79 / 65$ & $64.7(63.5-65.9)$ & $28.2(27.5-28.8)$ & 86 (73-98) & $0.04^{*}$ & $3.18(2.26-4.10)$ & $302(283-321)$ \\
\hline 3 & $17 / 19$ & $64.3(61.9-66.7)$ & $29.3(27.4-31.2)$ & $80(60-101)$ & 0.07 & $3.57(1.35-5.79)$ & $305(264-346)$ \\
\hline 4 & $12 / 10$ & $67.8(64.4-71.2)$ & $29.5(27.8-31.2)$ & $87(47-128)$ & 0.28 & $2.92(1.90-3.94)$ & $339(271-406)$ \\
\hline
\end{tabular}

The data is shown as mean [95-Cl]. C-Col10: C-terminus of ColX assay; C2M: MMP-derived collagen type II fragment assay; hsCRP: high sensitive CRP assay. KL score: Kellgren-Lawrence score. One-way ANOVA was applied to compare the mean C-Col10 levels of each KL group with the mean of KL 0 group. P value was considered statistically significant if $\mathrm{P}<0.05$ and significant level was presented as: *. 
Table 4 Correlations between serum levels of the 3 biomarkers

\begin{tabular}{lccc}
\hline & & C-Col10 & C2M \\
\hline C-Col10 & Correlation Coefficient & n. a. & 0.545 \\
& Significance Level P & n. a. & $<0.0001$ \\
hsCRP & Correlation Coefficient & 0.233 & 0.071 \\
& Significance Level P & $<0.0001$ & 0.2487 \\
\hline
\end{tabular}

Pearson's correlations were done on log transformed data. C-Col10: C-terminus of ColX assay; C2M: MMP-derived collagen type II fragment assay; hsCRP: high sensitive CRP assay.

hsCRP levels $(\mathrm{r}=0.23, \mathrm{P}<0.0001)$, and between $\mathrm{C}-\mathrm{Col} 10$ and $\mathrm{C} 2 \mathrm{M}$ levels $(\mathrm{r}=0.55, \mathrm{P}<0.0001)$ (Table 4). No correlation between C2M and hsCRP has been found. Age and BMI adjustment did not change the significant correlations. OA patients with above normal hsCRP $(>5)$ levels showed significantly increased C-Col10 levels $(\mathrm{p}<0.0001)$ (Figure 4).

\section{Immunolocalization of ColX in human OA cartilage by immunohistochemistry}

Cartilage biopsies including subchondral bone were stained with Safranin O/ Fast Green and classified according to severity of the cartilage damage (Figure 5A, $B, C)$. There was a clear immune-reactivity of ColX in the deep zone and calcified cartilage matrix surrounding the hypertrophic chondrocytes in the mild OA section (Figure 5D, G). Staining of ColX was observed in the middle zone cartilage matrix in the moderate OA section (Figure 5E, H). The obvious staining of ColX was also observed in the matrix of clustered chondrocytes close to the fibrillated surface in the severe OA section (Figure 5F, I). C2M was observed in all layers and consistently in 3 specimens (Figure 5J-O). No obvious and specific staining was found in sections incubated with normal mouse IgG (negative control, Figure 5P-R).

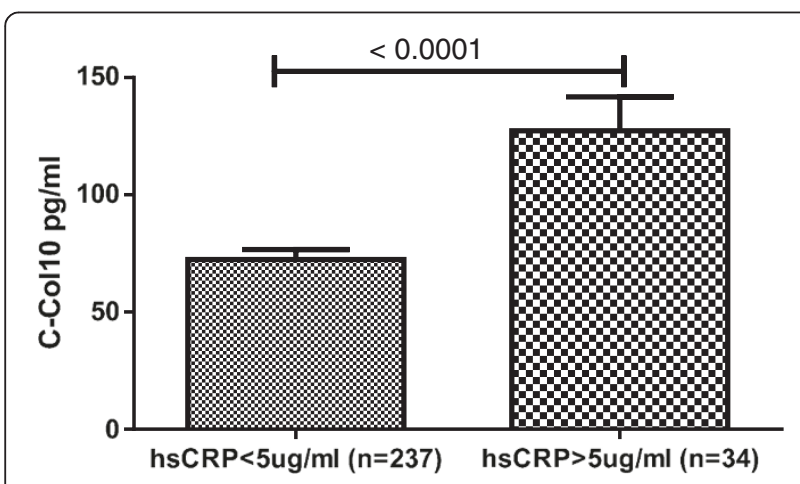

Figure 4 Elevated C-Col10 levels in patients with above normal hsCRP levels, $\mathbf{5} \boldsymbol{\mu g} / \mathbf{m l}$. T-test was used on log transformed data to determine the significant difference between these two groups.

\section{Discussion}

In this study, we have developed and technically validated a novel and specific ELISA assay, C-Col10, which can determine the level of ColX in serum. We found significantly higher levels of ColX in patients with KL2 compared to patients with no radiographic sign of OA (KLO). Although the mean of ColX were markedly higher in KL3 and KL4 group than in KL0 group, these were not significantly different. We observed a high variation in the levels in these severe OA groups, which could indicate that different subgroups exist and ColX not alone was related to cartilage loss (hence joint space width) as observed by radiography. This was further supported by the significant correlation of between ColX and hsCRP and C2M levels, suggesting that chondrocyte hypertrophy was both associated with inflammation and cartilage degradation. In addition, immunostaining using the same monoclonal antibody as used in the C-Col10 assay revealed that ColX was predominately located around the hypertrophic chondrocytes located in the deep zone and around the clustered chondrocytes located in the middle and upper zone, indicating that $\mathrm{C}$-Col10 measures were associated with differential changes of chondrocytes rather than solely degree of cartilage loss. To our knowledge, this is the first study to provide evidence of correlations between cartilage hypertrophy, inflammation and cartilage matrix degradation measured in OA serum samples.

A limitation of this study is the unavailability of recombinant human ColX protein for characterization of the antibody, NB509-11G8. Most commercial recombinant ColX proteins are fused with a partner at $\mathrm{C}$-terminus, like 6-histidine tag. However, NB509-11G8 is a C-terminus specific antibody and the extra amino acids elongated at the C-terminus would influence the binding to NB50911G8. Another limitation is the lack of detailed knowledge on the structure and the mechanism of release of ColX into circulation, thus there was no opportunity to make comparable judgment on the results that we have achieved. On the other hand our findings may add to the overall understanding of ColX in health and disease. Our findings identified a $17 \mathrm{kDa}$ fragment in both the U2-OS cell lysate and human OA cartilage extract using the NB509-11G8 antibody, which align with the size of the fragment from C-terminus to potential cleavage site at $\mathrm{Gly}^{479}$-Ile ${ }^{480}$ bond, which has been identified in chick cartilage [13,33]. In addition several other bands were identified indicating several structural entities of ColX, as well as several cleavage sites within the helical structure. The third limitation is that besides articular chondrocytes, subchondarl bone and osteophytes contribute to the serum measurement of ColX as well. We only did immunohistochemistry on human OA cartilage. We could image it will be quite interesting to investigate the presence and expression pattern of ColX in subchondral bone and osteophytes. 


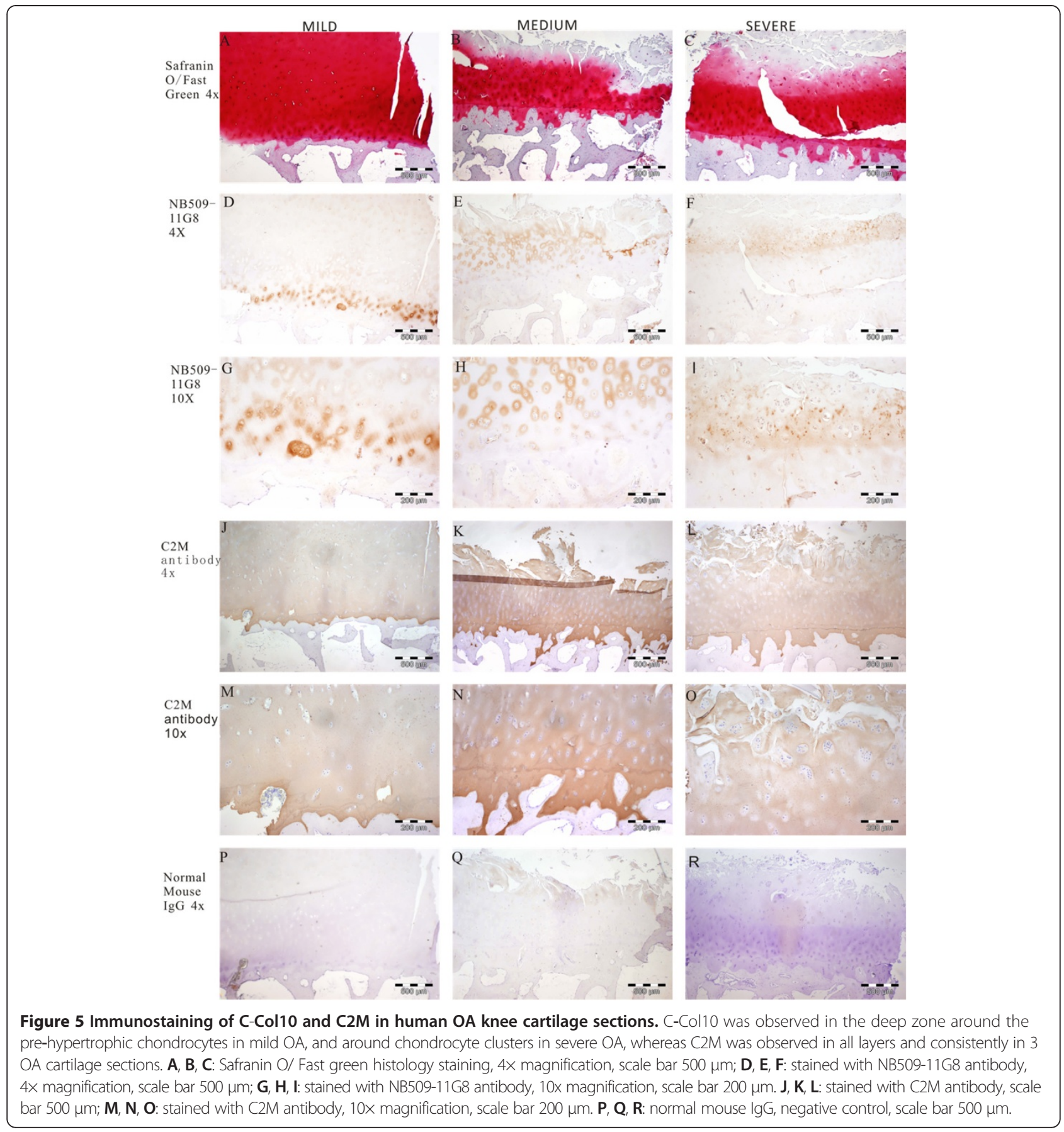

Several proteins have been associated with chondrocytes hypertrophy, among which expression analysis of COL1OA1 and MMP13 are probably the most widely used markers of cartilage hypertrophy. However, synthesis of MMP13 can be induced not only by hypertrophic chondrocytes, but also by non-hypertrophic chondrocytes and other cells present in the joint through inflammation and mechanical stress $[34,35]$. Type X collagen may potentially be a more specific marker of cartilage hypertrophy, as results on ColX seems to be limited to cartilage in the human adult. We have here presented data on the development and technically validation of a robust competitive assay, $\mathrm{C}$-Col10. The level of C-Col10 was significantly correlated with level of $\mathrm{C} 2 \mathrm{M}$, a surrogate marker of cartilage degradation, which indicates a close relationship between chondrocytes hypertrophy and articular cartilage degradation. The direct link has been confirmed by the immunostaining of $\mathrm{C}$-Col10 and $\mathrm{C} 2 \mathrm{M}$ on cartilage biopsies taken from OA patients undergoing total knee replacement (TKR) surgery. 
OA is normally considered as non-inflammatory joint disease, although it is evident that a subset of patients does indeed have synovitis (i.e. chronic inflammation). The hsCRP assay is used as standard diagnostic markers in inflammatory joint diseases such as RA; however the marker has limited usages in OA, since only a small proportion of the patients have elevated levels, although a few studies have shown hsCRP associated with clinical severity in patients with knee or hip OA [36,37] and joint pain [38]. In our study, significantly higher C-Col10 levels were observed in patients with above normal hsCRP $(>5 \mu \mathrm{g} / \mathrm{ml})$ levels. This association between hsCRP and C-Col10 levels could indicate a causal relationship between inflammation and chondrocyte hypertrophy, which has been suggested through the activity of HIF- $2 \alpha[39,40]$. The interpretation of this relation is consistent with previous studies that inflammatory factors, like interleukin-8 [41], Interleukin-1ßinduced S100A11 protein [42] can accelerate chondrocyte hypertrophy.

There are contradictory data regarding hypertrophic chondrocyte in OA. Some publications have indicated that terminal differentiation of chondrocytes into hypertrophy is associated with OA $[6,43,44]$. Therefore hypertrophy chondrocyte is considered as one of the hallmarks in OA. In contrast, a study by Brew et al. demonstrated that hypertrophy associated genes expression, like collagen type $\mathrm{X}$, was significantly down-regulated in OA cartilage [45]. The discrepancy has indicated the complexity and heterogeneity of the progression of OA disease, where different driving forces might be involved in. An earlier ex vivo study by Chen-An et al. demonstrated that the anti-resorptive drug, salmon calcitonin, was able to protect cartilage from hypertrophy in articular cartilage explants [46]. Our present study confirms and extends existing reports that the phenotype of chondrocytes changing into hypertrophy at least occurred in the subpopulation of patients with OA. Thus, anti-hypertrophic differentiation could be a critical factor considered for the future therapeutic OA drug development.

\section{Conclusions}

In conclusion, chondrocyte hypertrophy and subsequent type $\mathrm{X}$ collagen seems to be increased in a subset of patients with inflammatory OA. The increase of ColX levels in serum possibly serve as a marker of local chondrocyte hypertrophy and differentiation, and may even aid in describing the progression of OA disease.

\footnotetext{
Abbreviations

OA: Osteoarthritis; ELISA: Enzyme-Linked Immuno Sorbent Assay; KL score: Kellgren-Lawrence score; ColX: Collagen type X; hsCRP: high sensitivity CRP; C2M: MMP-derived collagen type II neoepitope.
}

\section{Competing interests}

JWA, DSU, QZH, MAK and ACBJ were at the time of the experimentation full-time employee at Nordic Bioscience, which is a privately owned company involved in the development of novel biomarkers for rheumatic diseases. MAK holds stocks of Nordic Bioscience. YHE, ASO, NUH, OSI, KKP, LAN, TES and $\mathrm{HCH}$ have no conflict of interest to report.

\section{Authors' contributions}

MK and ACBJ make contributions to conception, study design and data analysis. YHE is contributed in ColX antibody characterization, assay development, data analysis and drafting. ASO collected information of samples and did proofreading of the manuscript. NUH, JWA, DSU and QZH participated in the Col X antibody development. OSI, KKJ, LAN, TSK, HCH provided the samples. All authors read and approved the final manuscript.

\section{Acknowledgements}

We would like to acknowledge Dr. Kim Henriksen for his inspired discussion and appreciate Shu Sun providing me the human skeletal muscle extract. We also thank Yong Jiao Yan for her help in peptide conjugation as immunogen in this study. Lastly, we would like to thank our skilled technicians Kathrine Mikkelsen, Sedi Tavallaee, Maibritt Andersen whom contributed in the measurement of hsCRP, and C2M assays in serum samples.

\section{Author details}

${ }^{1}$ Nordic Bioscience, Herlev Hovedgade 207, DK-2730 Herlev, Denmark. ${ }^{2}$ Nordic Bioscience China, Zhongguancun Life Science Park, 102206 Beijing, P.R. China. ${ }^{3}$ Department of Orthopedic Surgery, Aalborg University Hospital, Hobrovej 19, 9000 Aalborg, Denmark. ${ }^{4}$ Department of Health Science and Technology, Center for Sensory-Motor Interaction, Aalborg University, Aalborg, Denmark. ${ }^{5}$ Center for Clinicl and Basic Research and C4Pain, Aalborg, Denmark.

Received: 26 November 2013 Accepted: 18 September 2014 Published: 22 September 2014

\section{References}

1. Kotlarz H, Gunnarsson CL, Fang H, Rizzo JA: Insurer and out-of-pocket costs of osteoarthritis in the US: evidence from national survey data. Arthritis Rheum 2009, 60(12):3546-3553.

2. Bertrand J, Cromme C, Umlauf D, Frank S, Pap T: Molecular mechanisms of cartilage remodelling in osteoarthritis. Int J Biochem Cell Biol 2010, 42(10):1594-1601.

3. Mackie EJ, Ahmed YA, Tatarczuch L, Chen KS, Mirams M: Endochondral ossification: how cartilage is converted into bone in the developing skeleton. Int J Biochem Cell Biol 2008, 40(1):46-62.

4. Gelse K, Ekici AB, Cipa F, Swoboda B, Carl HD, Olk A, Hennig FF, Klinger P: Molecular differentiation between osteophytic and articular cartilage-clues for a transient and permanent chondrocyte phenotype. Osteoarthritis and cartilage/OARS, Osteoarthritis Res Soc 2012, 20(2):162-171.

5. Saito M, Sasho T, Yamaguchi S, Ikegawa N, Akagi R, Muramatsu Y, Mukoyama S, Ochiai N, Nakamura J, Nakagawa K, Nakajima A, Takahashi K: Angiogenic activity of subchondral bone during the progression of osteoarthritis in a rabbit anterior cruciate ligament transection model. Osteoarthritis and cartilage/OARS, Osteoarthritis Res Soc 2012, 20(12):1574-1582.

6. Fuerst M, Bertrand J, Lammers L, Dreier R, Echtermeyer F, Nitschke Y, Rutsch F, Schafer FK, Niggemeyer O, Steinhagen J, Lohmann CH, Pap T, Rüther W: Calcification of articular cartilage in human osteoarthritis. Arthritis Rheum 2009, 60(9):2694-2703.

7. Higashikawa A, Saito T, Ikeda T, Kamekura S, Kawamura N, Kan A, Oshima Y, Ohba S, Ogata N, Takeshita K, Nakamura K, Chung UI, Kawaguchi H: Identification of the core element responsive to runt-related transcription factor 2 in the promoter of human type X collagen gene. Arthritis Rheum 2009, 60(1):166-178.

8. Dreier R: Hypertrophic differentiation of chondrocytes in osteoarthritis: the developmental aspect of degenerative joint disorders. Arthritis Res Ther 2010, 12(5):216.

9. van der Kraan PM, van den Berg WB: Chondrocyte hypertrophy and osteoarthritis: role in initiation and progression of cartilage degeneration? Osteoarthritis and cartilage/OARS, Osteoarthritis Res Soc 2012, 20(3):223-232.

10. Pitsillides AA, Beier F: Cartilage biology in osteoarthritis-lessons from developmental biology. Nat Rev Rheumatol 2011, 7(11):654-663. 
11. Bruckner $P$, van der Rest $M$ : Structure and function of cartilage collagens Microsc Res Tech 1994, 28(5):378-384.

12. Kwan AP, Sear $C H$, Grant ME: Identification of disulphide-bonded type $\mathbf{X}$ procollagen polypeptides in embryonic chick chondrocyte cultures. FEBS Lett 1986, 206(2):267-272.

13. Schmid TM, Mayne R, Jeffrey JJ, Linsenmayer TF: Type $X$ collagen contains two cleavage sites for a vertebrate collagenase. J Biol Chem 1986, 261(9):4184-4189.

14. Schmid TM, Popp RG, Linsenmayer TF: Hypertrophic cartilage matrix. Type $X$ collagen, supramolecular assembly, and calcification. Ann N Y Acad Sci 1990, 580:64-73.

15. Kwan AP, Cummings CE, Chapman JA, Grant ME: Macromolecular organization of chicken type X collagen in vitro. J Cell Biol 1991, 114(3):597-604.

16. Luckman SP, Rees E, Kwan AP: Partial characterization of cell-type X collagen interactions. Biochem J 2003, 372(Pt 2):485-493.

17. Aigner $T$, Reichenberger $E$, Bertling W, Kirsch T, Stoss H, von der Mark K: Type $X$ collagen expression in osteoarthritic and rheumatoid articular cartilage. Virchows Arch B Cell Pathol Incl Mol Pathol 1993, 63(4):205-211.

18. Hoyland JA: Distribution of type $X$ collagen mRNA in normal and osteoarthritic human cartilage. Bone Miner 1991, 15(2):151-163.

19. Walker GD, Fischer M, Gannon J, Thompson RC Jr, Oegema TR Jr: Expression of type-X collagen in osteoarthritis. J Orthop Res: official publication Orthop Res Soc 1995, 13(1):4-12.

20. Kamekura S, Hoshi K, Shimoaka T, Chung U, Chikuda H, Yamada T, Uchida M, Ogata N, Seichi A, Nakamura K, Kawaguchi H: Osteoarthritis development in novel experimental mouse models induced by knee joint instability. Osteoarthritis and cartilage/OARS, Osteoarthritis Res Soc 2005, 13(7):632-641.

21. Matsumoto T, Cooper GM, Gharaibeh B, Meszaros LB, Li G, Usas A, Fu FH, Huard J: Cartilage repair in a rat model of osteoarthritis through intraarticular transplantation of muscle-derived stem cells expressing bone morphogenetic protein 4 and soluble Flt-1. Arthritis Rheum 2009, 60(5):1390-1405

22. Huebner JL, Johnson KA, Kraus VB, Terkeltaub RA: Transglutaminase 2 is a marker of chondrocyte hypertrophy and osteoarthritis severity in the Hartley guinea pig model of knee OA. Osteoarthritis and cartilage/OARS, Osteoarthritis Res Soc 2009, 17(8):1056-1064.

23. Kim DY, Taylor HW, Moore RM, Paulsen DB, Cho DY: Articular chondrocyte apoptosis in equine osteoarthritis. Vet J London, England: 1997 2003, 166(1):52-57.

24. Conrozier T, Chappuis-Cellier C, Richard M, Mathieu P, Richard S, Vignon E: Increased serum C-reactive protein levels by immunonephelometry in patients with rapidly destructive hip osteoarthritis. Rev Rhum Engl Ed 1998, 65(12):759-765

25. Spector TD, Hart DJ, Nandra D, Doyle DV, Mackillop N, Gallimore JR, Pepys MB: Low-level increases in serum C-reactive protein are present in early osteoarthritis of the knee and predict progressive disease. Arthritis Rheum 1997, 40(4):723-727.

26. Smith JW, Martins TB, Gopez E, Johnson T, Hill HR, Rosenberg TD: Significance of C-reactive protein in osteoarthritis and total knee arthroplasty outcomes. Ther Adv musculoskelet Dis 2012, 4(5):315-325.

27. Scanzello CR, Goldring SR: The role of synovitis in osteoarthritis pathogenesis. Bone 2012, 51(2):249-257.

28. Cecil DL, Johnson K, Rediske J, Lotz M, Schmidt AM, Terkeltaub R: Inflammation-induced chondrocyte hypertrophy is driven by receptor for advanced glycation end products. J Immunol 2005, 175(12):8296-8302.

29. Bay-Jensen AC, Liu Q, Byrjalsen I, Li Y, Wang J, Pedersen C, Leeming DJ, Dam EB, Zheng Q, Qvist P, Karsdal MA: Enzyme-linked immunosorbent assay (ELISAs) for metalloproteinase derived type II collagen neoepitope, CIIM-increased serum CIIM in subjects with severe radiographic osteoarthritis. Clin Biochem 2011, 44(5-6):423-429.

30. Bay-Jensen AC, Leeming DJ, Kleyer A, Veidal SS, Schett G, Karsdal MA: Ankylosing spondylitis is characterized by an increased turnover of several different metalloproteinase-derived collagen species: a cross-sectional study. Rheumatol Int 2012, 32(11):3565-3572.

31. Bay-Jensen AC, Wichuk S, Byrjalsen I, Leeming DJ, Morency N, Christiansen C, Karsdal MA, Maksymowych WP: Circulating protein fragments of cartilage and connective tissue degradation are diagnostic and prognostic markers of rheumatoid arthritis and ankylosing spondylitis. PLOS One 2013, 8(1):e54504.
32. Pautke C, Schieker M, Tischer T, Kolk A, Neth P, Mutschler W, Milz S: Characterization of osteosarcoma cell lines MG-63, Saos-2 and U-2 OS in comparison to human osteoblasts. Anticancer Res 2004, 24(6):3743-3748.

33. Welgus HG, Fliszar CJ, Seltzer JL, Schmid TM, Jeffrey JJ: Differential susceptibility of type $X$ collagen to cleavage by two mammalian interstitial collagenases and 72-kDa type IV collagenase. J Biol Chem 1990, 265(23):13521-13527.

34. Fitzgerald JB, Jin M, Chai DH, Siparsky $P$, Fanning $P$, Grodzinsky AJ: Shear- and compression-induced chondrocyte transcription requires MAPK activation in cartilage explants. J Biol Chem 2008, 283(11):6735-6743.

35. Goldring MB, Otero M, Tsuchimochi K, ljiri K, Li Y: Defining the roles of inflammatory and anabolic cytokines in cartilage metabolism. Ann Rheum Dis 2008, 67(Suppl 3):iii75-iii82.

36. Conrozier T, Carlier MC, Mathieu P, Colson F, Debard AL, Richard S, Favret H, Bienvenu J, Vignon E: Serum levels of YKL-40 and $C$ reactive protein in patients with hip osteoarthritis and healthy subjects: a cross sectional study. Ann Rheum Dis 2000, 59(10):828-831.

37. Wolfe $\mathrm{F}$ : The $\mathrm{C}$-reactive protein but not erythrocyte sedimentation rate is associated with clinical severity in patients with osteoarthritis of the knee or hip. J Rheumatol 1997, 24(8):1486-1488.

38. Sturmer T, Brenner H, Koenig W, Gunther KP: Severity and extent of osteoarthritis and low grade systemic inflammation as assessed by high sensitivity C reactive protein. Ann Rheum Dis 2004, 63(2):200-205.

39. Saito T, Fukai A, Mabuchi A, Ikeda T, Yano F, Ohba S, Nishida N, Akune T, Yoshimura N, Nakagawa T, Nakamura K, Tokunaga K, Chung UI, Kawaguchi $\mathrm{H}$ : Transcriptional regulation of endochondral ossification by HIF-2alpha during skeletal growth and osteoarthritis development. Nat Med 2010, 16(6):678-686.

40. Yang S, Kim J, Ryu JH, Oh H, Chun CH, Kim BJ, Min BH, Chun JS: Hypoxiainducible factor-2alpha is a catabolic regulator of osteoarthritic cartilage destruction. Nat Med 2010, 16(6):687-693.

41. Cecil DL, Rose DM, Terkeltaub R, Liu-Bryan R: Role of interleukin-8 in PiT-1 expression and CXCR1-mediated inorganic phosphate uptake in chondrocytes. Arthritis Rheum 2005, 52(1):144-154.

42. Cecil DL, Terkeltaub R: Transamidation by transglutaminase 2 transforms S100A11 calgranulin into a procatabolic cytokine for chondrocytes. $\mathrm{J}$ Immunol 2008, 180(12):8378-8385.

43. Little CB, Barai A, Burkhardt D, Smith SM, Fosang AJ, Werb Z, Shah M, Thompson EW: Matrix metalloproteinase 13-deficient mice are resistant to osteoarthritic cartilage erosion but not chondrocyte hypertrophy or osteophyte development. Arthritis Rheum 2009, 60(12):3723-3733.

44. Mwale F, Rampersad S, Richard H, Guoying Y, Al Rowas S, Madiraju P, Antoniou J, Laverty S: The constitutive expression of type $x$ collagen in mesenchymal stem cells from osteoarthritis patients is reproduced in a rabbit model of osteoarthritis. J Tissue Eng 2011, 2011:587547.

45. Brew CJ, Clegg PD, Boot-Handford RP, Andrew JG, Hardingham T: Gene expression in human chondrocytes in late osteoarthritis is changed in both fibrillated and intact cartilage without evidence of generalised chondrocyte hypertrophy. Ann Rheum Dis 2010, 69(1):234-240.

46. Chen-An P, Andreassen KV, Henriksen K, Li Y, Karsdal MA, Bay-Jensen AC: The inhibitory effect of salmon calcitonin on tri-iodothyronine induction of early hypertrophy in articular cartilage. PLoS One 2012, 7(6):e40081.

\section{doi:10.1186/1471-2474-15-309}

Cite this article as: He et al:: Type X collagen levels are elevated in serum from human osteoarthritis patients and associated with biomarkers of cartilage degradation and inflammation. BMC Musculoskeletal Disorders 2014 15:309. 